\title{
PIPE SIZING FOR INSTRUMENT AIR DELIVERY TO THE CC AND EC CRYOSTATS
}

\author{
J.B. FITZPATRICK
}

12/07/87

D-ZERO ENGINERING NOTE 3740.000-EN-124

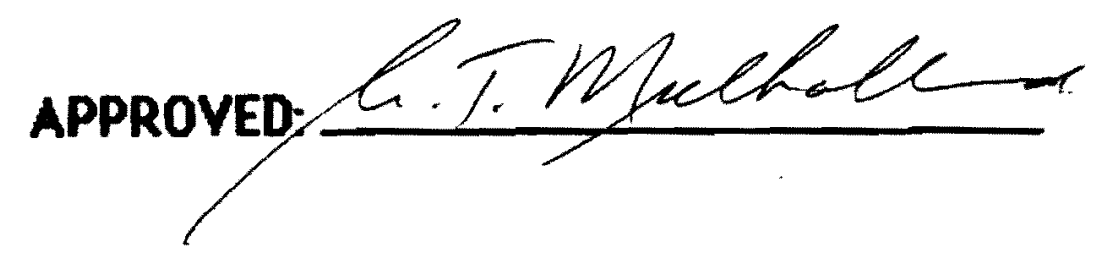


WTRODUCTION: This engineering note calcuiates the minimum required line size for the manifold and the associated piping that deliver instrument air to the three cryostats at the D-Zero project.

SETUP: The piping setup is approximated by figures 1 and 2 , attached.

PROBLEM: The air delivery system is driven by a $100 \mathrm{psi}, 100 \mathrm{cfm}$ air compressor. There are two questions to be answered:

1) For a given $30 \mathrm{ft}$. manifold the diameter is to be calculated Air will be tapped at $5 \mathrm{ft}$., $15 \mathrm{ft}$. and $25 \mathrm{ft}$. along the pipe The requirement is that there be a pressure drop of no more than 1 psi. total along the length of that pipe. The taps $y^{\circ}$ respectively off to the South End Calorimeter Cryostat (SEC), Central Calorimeter Cryostat (CC), and the North End Calorimeter Cryostat (NEC). Each tap leads to 5 separate linear actuators with electropneumatic positioners (Valtek.) The flow through each actuator in the steady state is 0.25 scfm-air. (see ref li. Actuator transient flow requirements will be addressed by providing a factor of two to steady state flow.

2) The size of the pipe from the platform up to the manifold is to be calculated. Again the requirement is that there be a pressure drop of no more than 1 psi. total along the length of that pipe. (see fig 2). A factor of 4 will be introduces into the mass flow to accomodate all other possible users who may tap the line. Capped off tees will be placed at convenient locations along the run in accord with the assumption that there may be future instrument air needs. 


\section{CALCILATIONS:}

USE: $\Delta P / \Delta L=\left[\left(5 * 10^{9}\right) * \mu^{0.2} * \operatorname{Mdot} 1.8\right] /\left[R H O * R^{4.8}\right]$

where: $\Delta P=$ The pressure drop in the pipe. (atm.)

$\Delta L \quad=$ The length of the plpe where the above $\Delta P$ occurs. (cm)

$\mu \quad=$ The viscosity of the fluid flowing in the pipe (air) at 300K (room temp), and compressor pressure of (100psi, $7 \mathrm{~atm}.) .(\mathrm{g} /[\mathrm{cm}-\mathrm{s}])$

RHO = The density of the fluid (air) at 300K, and $7 \mathrm{~atm} .\left(\mathrm{g} / \mathrm{cm}^{3}\right)$

$R \quad=$ Required radius of the pipe (inside radius). (cm)

Mdot $=$ The mass flow of fluid (air) through the pipe. $(g / s)$ 


\section{PROBLEM 1 \\ Solve for $\mathrm{B}$ :}

\section{HDOI:}

The flow through each tap is therefore:

5 actuators * 0.26 SCFM $) *(2$, safety factor $)=2.6$ SCFM

Then the total flow in the $30 \mathrm{ft}$. section is:

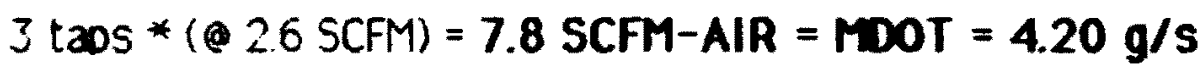

From 0-5 ft., Mdot $=4.20 \mathrm{~g} / \mathrm{s}$

From 5-15 ft., Mdot $=\mathbf{2 . 8 0} \mathrm{g} / \mathrm{s}$

From $15-25 \mathrm{ft}$., $\quad$ Mdot $=1.40 \mathrm{~g} / \mathrm{s}$

\section{Btio:}

From Reference 2. at $300 \mathrm{~K}$ and $7.00 \mathrm{~atm}$. $\mathrm{RHCO}=.00797 \mathrm{~g} / \mathrm{cm}^{3}$

11

From Reference 2, at 300K and $7.00 \mathrm{~atm}$.

$\mu=180.51 * 10^{-6} \mathrm{~g} /[\mathrm{cm}-\mathrm{s}]$

\section{$\Delta \mathbf{P}$}

Assume that the pressure drop is evenly distributed over the three sections $(0-5 \mathrm{ft} ., 5-15 \mathrm{ft}$., $15-25 \mathrm{ft}$ ) and is therefore equal to 33 DSi in each section.
$\Delta P=.33 \mathrm{pSI}=.023 \mathrm{~atm}$.

Al:

For section 1, the length is $5 \mathrm{ft}$

$\Delta L=5 \mathrm{ft} .=152.4 \mathrm{~cm}$.

For sections 2 and 3 , the length is $10 \mathrm{ft}$.

$\Delta \mathrm{L}=10 \mathrm{ft} .=304.8 \mathrm{~cm}$. 
RESUITS:

The results of this calculation show that:

Section I (0-5 ft.) requires a inside diameter of .30 inches.

Section 2 (5-15 ft.) requires a inside diameter of 30 inches.

Section $3(15-25 \mathrm{ft}$.$) requires a inside diameter of .23$ inches.

\section{CONCLUSION:}

The calculations show that the maximum calculated pipe size has an inside diameter of 300 inches. The 30 foot length of pipe must be at least 300 inches in inside diameter

Note that individual actuator feed lines that meet the same $\Delta P$ criteria (and are approximately as long) require a tributary pipe radius of:

$$
R_{2}=(\operatorname{Mdot} 2 / \operatorname{Mdot} 1)^{(1.8 / 4.8)} * R_{1}
$$

Where: $R_{1}=0.115$ inches (CHECK MINIMU) Mdot2 $/$ Mdot $1=(1 / 5)=0.2$

Thus $R_{2}=0.063$ inches

This requirement suggests at least $1 / 4^{\prime \prime} 0.0$. Tube $\times 0.035^{\prime \prime}$ wall should be used for these tributaries.

The recommended manifold size is thus $1 / 2$ inch schedule 405 pipe which has an inside diameter of 0.622 inches. The actual pipe size may be larger due to other reasoning. This report calculates the minimum size only. 
PROBLEM $* 2$

SOLVE FOR R:

$\Delta P=1 \mathrm{pSI}=0.068 \mathrm{Atm}$.

$\Delta L=981.75^{\circ}=2493.64 \mathrm{~cm}$ (includes equivalent length

of 3-1"-90* elbows)

(see Ref. 3)

Mdot $=7.8 * 4=31.2 \mathrm{SCFM}$-air $=16.8 \mathrm{~g} / \mathrm{s}$

ALL OTHER VALUES REMAIN THE SAME AS IN PROBLEM $\approx 1$

RESULTS:

The results of this calculation show that:

An inside diameter of at least .52" is required for the piping from the platform to the manifold.

\section{CONCLUSION:}

The recomended pipe size is $1 "$ schd 40 s. 


\section{BEFEREMCES}

1. Valtek Linear Actuators, Valtek Inc., Soringville, Utah., Rev. 1/82/5M, page 12.

2. Thermodynamic Properties of Nitrogen, (NBS-TN-1025).

3. McAdams, "Heat Transmission", McGraw-Hill, New York, 1954. (attached) 
Crlculotion ef Axlore size

(7)

(1) sec $10-5^{\circ}$

$$
\begin{aligned}
& \Delta L=5^{\circ}=152.4 \mathrm{~cm} . \\
& P_{300 k, \text { zhop: }}=.00797 \mathrm{~g} / \mathrm{cm}^{3}
\end{aligned}
$$

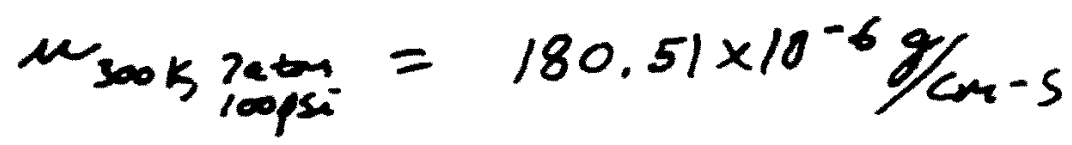

$$
\begin{aligned}
& \Delta P=\frac{1 p_{i}}{3}=\frac{.068}{3} \text { atw }=.023 \text { atan } . \\
& \dot{M}_{0-5^{\circ}}=7.8 \mathrm{scFm}=4.20 \mathrm{~g} / \mathrm{s} \\
& \frac{\Delta P}{\Delta L}=\frac{.023}{1524}=\frac{\left(5 \times 10^{-9}\right)\left(180.51 \times 10^{-6}\right)^{.2}(4.20)^{1.8}}{(.00797)\left(R^{4.8}\right)} \\
& R^{4.8}=.0098 \\
& \therefore R=.382 \mathrm{~cm}=.15 \text { incles } \\
& \text { - IDimeter }=.30^{\circ}
\end{aligned}
$$

(2) sec. $2 \quad 5^{\prime}-15^{\circ}$

$$
\begin{aligned}
& \dot{M}_{5}-15 \cdot \frac{2(7.8 \mathrm{scFm})}{3}=5.25 \times \mathrm{Fm}_{1}=2.80 \mathrm{~J} / \mathrm{s} \\
& \Delta L=10 \mathrm{ft}=304.8 \mathrm{~cm} \text {. } \\
& \frac{\Delta P}{\Delta L}=\frac{.023}{304.8}=\frac{\left(5 \times 10^{-4}\right)\left(180.51 \times 10^{-6}\right)^{.2}(280)^{1.8}}{(.00797)\left(R^{. .8}\right)} \\
& R^{48}=.0095 \\
& \therefore R=.379 \mathrm{~cm}=.149 \text { inclear } \\
& \therefore \text { E. Diancta }=.30^{\circ}
\end{aligned}
$$

(3) $\mathrm{sec} .3 \quad 65^{\circ}-25^{\circ}$

$$
\begin{aligned}
& M_{15-25}=\frac{7.9}{3}=2.6 \mathrm{scm}=1.40 \mathrm{gts}, \Delta L=10 \mathrm{ft}=3048 \mathrm{~cm} . \\
& R^{43}=.0027 \\
& \therefore R=.292 \mathrm{~cm}=.115 \text { inclee } \quad \therefore I D .=1 \sqrt{.237}
\end{aligned}
$$




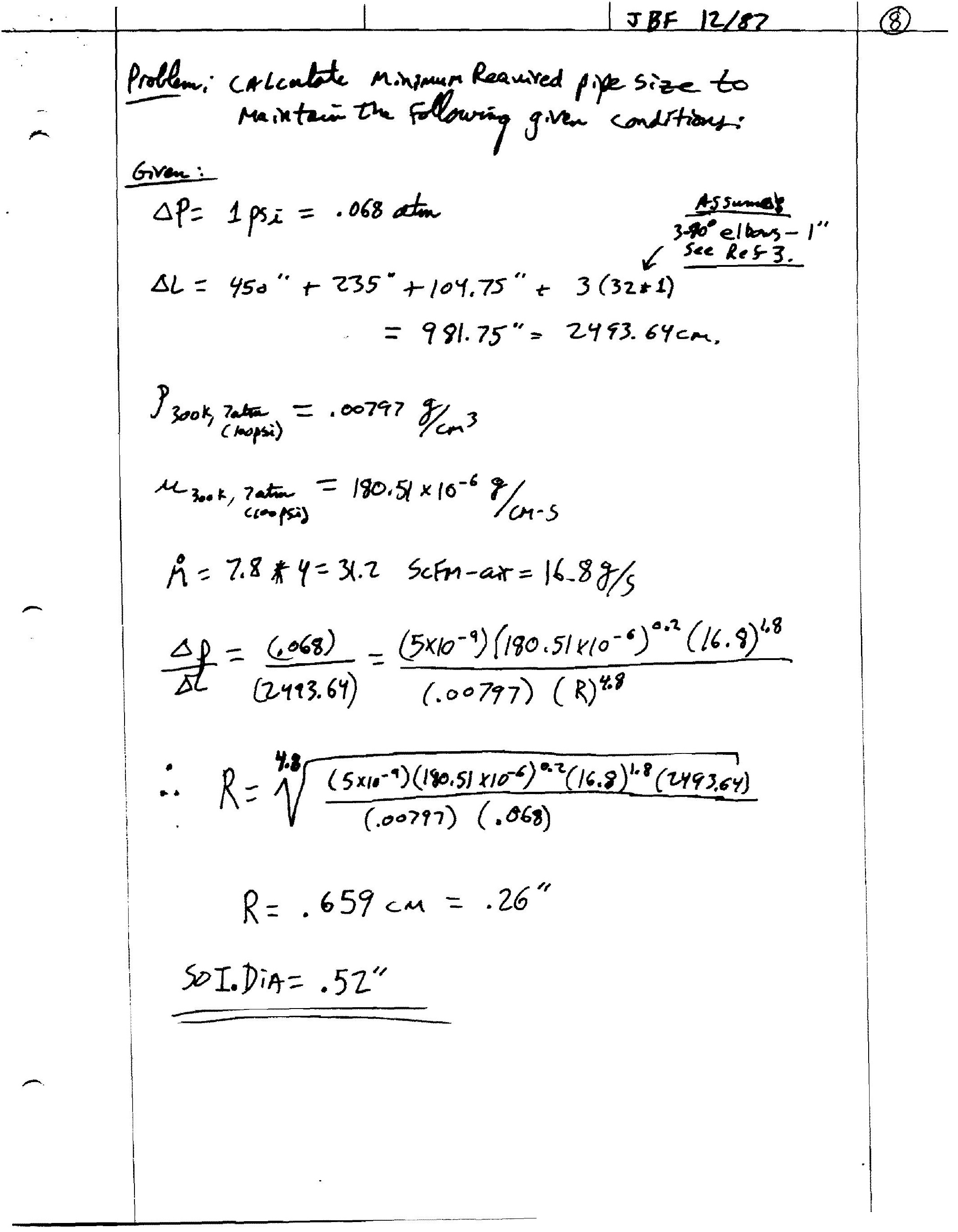




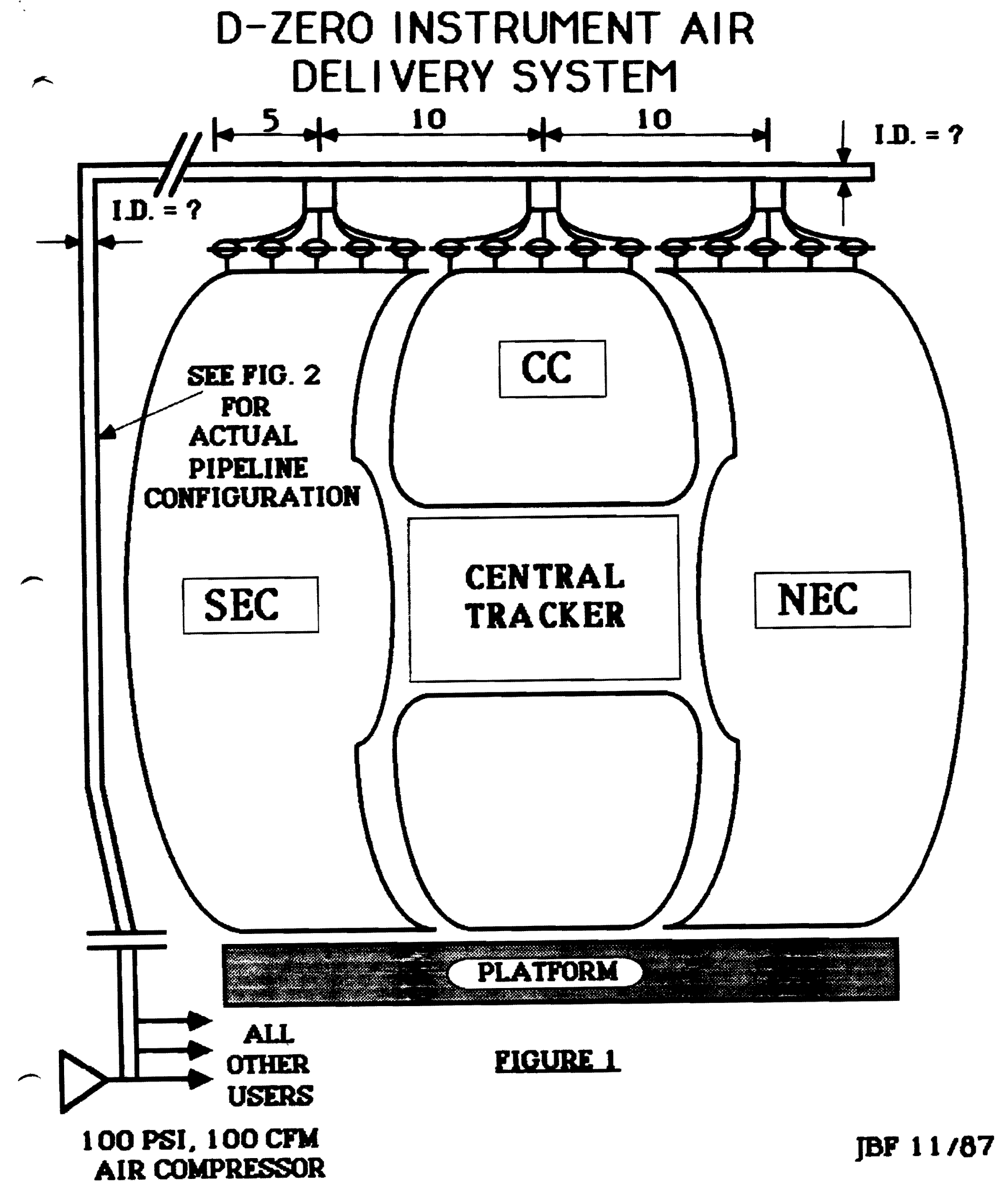




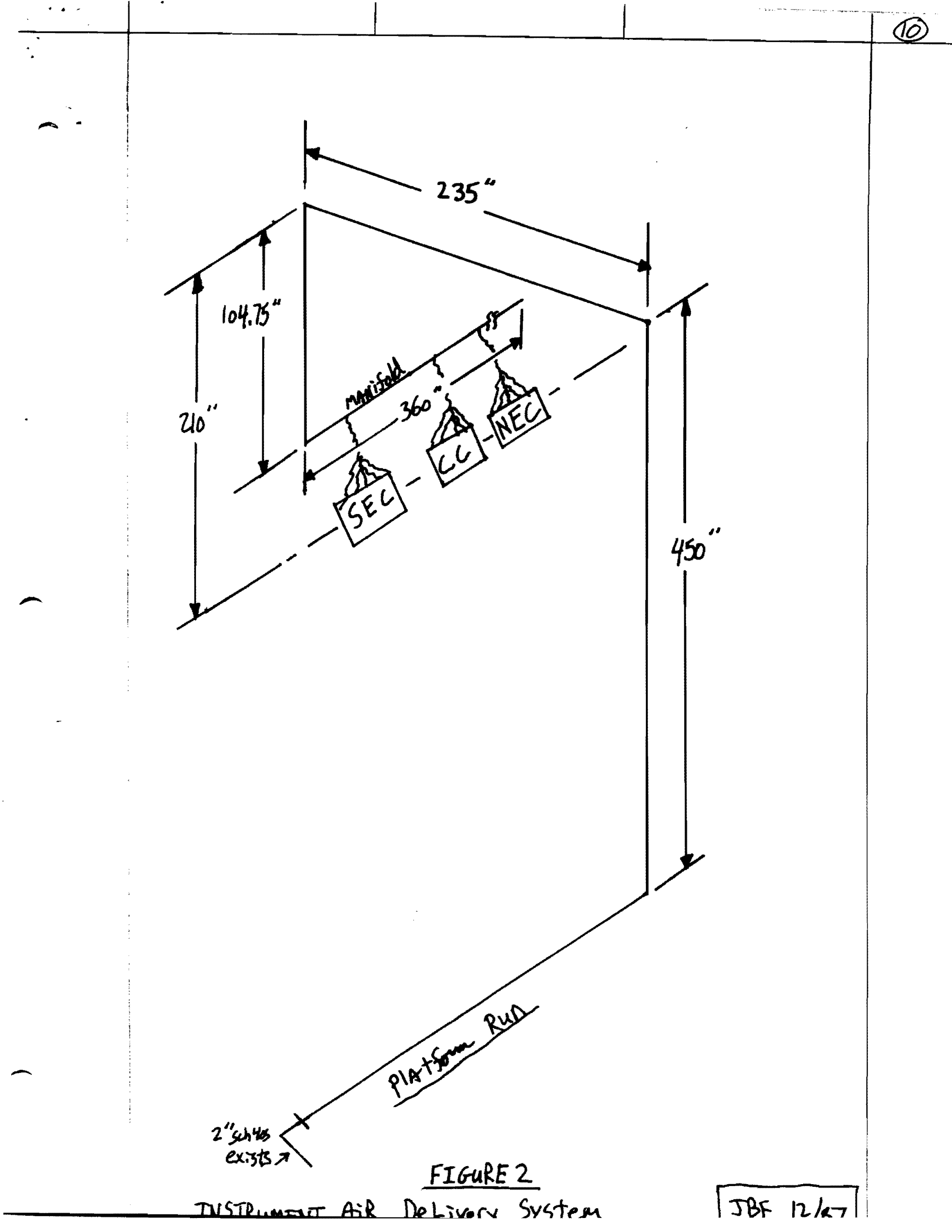




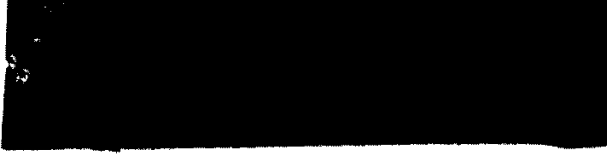

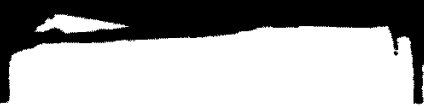

1

\section{Ref 1 .}

'N

(total angle of divernence any be celculated by inte$(6-2 c)$, and (6-8a). Where " no simple trentment will

ation of Eqs. (6-9b), (6-10),

te inside the straight becivoncal of erom section). The air enters und leave st $180^{\circ} \mathrm{F}$. Tie tubes Caleulate (a) the presine drop se over-all presure drop betweea croes sections twice those of the

$t$ air. expressed as $\mathrm{lb} /(\mathrm{ft})(\mathrm{sec})$. is $\Delta G$ is $\left(z_{1}\right)(2)$, the values of $D G / \mu$ reponding value of $f$ ere a0077

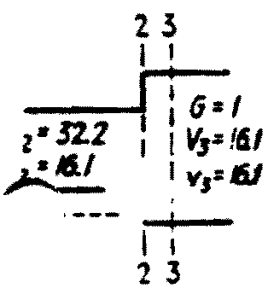

075. The hydraulic mone ir is 29.0, that is, $29 \mathrm{lb}$ of air oceumere.

.1 ou $\mathrm{ft} / \mathrm{lb}$ atially sormed haromeciix presoure.

I : $\mathrm{u}$ it lb

.0.1 cu ft. lb

By Eq. (6-9b)

$\frac{0.0075)(19)(2)^{2}(20.1)}{(3.1)(4.20)}$

$\{$ pounds force $s q \mathrm{ft}$

$\left.\frac{1}{1.2 \mathrm{ft} \sec ^{2}}\right)\left(\frac{1}{62.3 \mathrm{hh} \mathrm{ft}^{2}}\right)\left(\frac{12 \mathrm{in}}{1 \mathrm{ft}}\right)$

$=0.600$ in. water

sat uf the net beat iopat ! Base. (b-1a) ron ar rotas

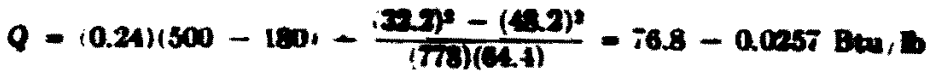

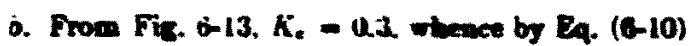

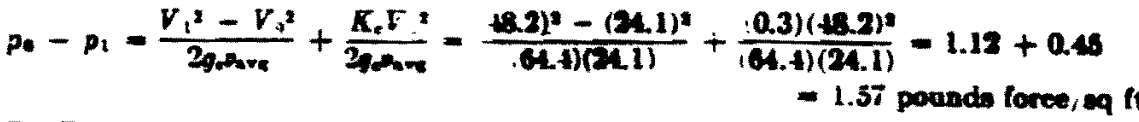

By Eq. (2-11)

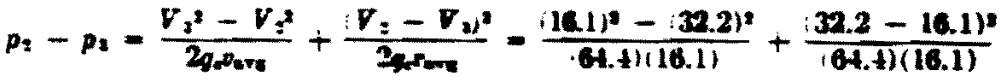

\begin{tabular}{|c|c|c|}
\hline Differeaces & $\frac{\text { Pounde force }}{\text { Square foot }}$ & $\begin{array}{c}\text { Incbea of } \\
\text { water }\end{array}$ \\
\hline $\begin{array}{l}p_{1}-p_{2}=1.12-0.15 \\
p_{1}-p_{2}=-0.99+1.27 \\
p_{2}-p_{2}=-0.73+0.25\end{array}$ & $\begin{array}{l}+1.57 \\
+3.28 \\
-0.50 \\
\end{array}$ & $\begin{array}{r}+0.301 \\
+0.650 \\
-0.013 \\
\end{array}$ \\
\hline$p_{2}-p$ & $\$ .35$ & 0.835 \\
\hline
\end{tabular}

$$
\begin{aligned}
& =-0.75+0.25=-0.5 \text { pound forcos/sq ft } \\
& \text { Sement }
\end{aligned}
$$

Since $1 \mathrm{~atm}$ is equivalent to a presure of $(14.69)(1+4)$ - 2115 poundh force/m $\mathrm{fth}$ li.tle error was made in negletiog the change in $p$ in calculating on. Amuming 500 air tubes, the volumetric rate of tow at the exit would be $(300)(3.14)(1) /(14)(82.2)=$ $351 \mathrm{cu} \mathrm{ft}$ /sec st normal presoure. With the han at the exit, the power theoretically required would be $(351)+.35 .550)=2.7 \mathrm{hp}$.

Fittings. These are allowed for by assigning a fictitious or equivalent iength $L$. of straight pipe to the existing straight pipe and using the sum $L .-L$, in Eq. $(6-2 d)$ io turbulent flow. For $D G_{/} \mu$ above 2100 to 3000 ,

\begin{tabular}{|c|c|c|c|}
\hline Fictins & $L_{0} / D$ & Fitting & $L_{n} / D$ \\
\hline 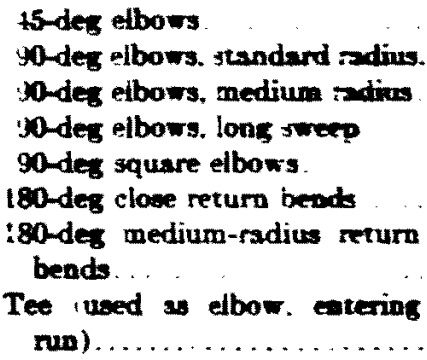 & 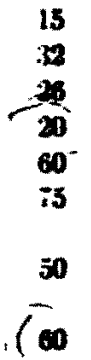 & 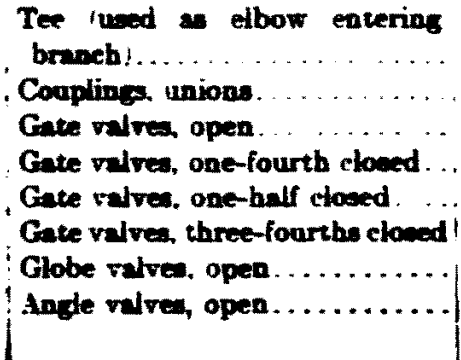 & $\begin{array}{c}90 \\
\text { Xediple } \\
7 \\
400 \\
800 \\
300 \\
170\end{array}$ \\
\hline
\end{tabular}

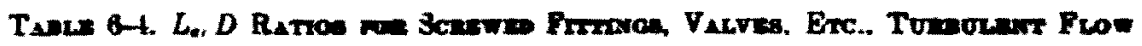
Ontro

- Parry." p. pan.

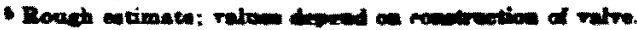

